\title{
Crowdfunded Ventures: Where Angels Dare to Tread
}

\author{
Sandy Yu (University of Minnesota) \\ Lee Fleming (UC Berkeley)
}

\section{KEYWORDS: Entrepreneurship, Angel Funding, Research Methods, financing, Crowdfunding. \\ By Sandy Yu, Scott Johnson, Chiayu Lai, Antonio Cricelli and Lee Fleming}

As Silicon Valley, Boston and metropolitan New York show, entrepreneurship can drive the prosperity of a region -- creating spinoffs and related businesses, job opportunities that draw new waves of younger workers, and a more vibrant culture. Many ambitious entrepreneurs, especially in the technology realm, feel that these meccas are the only places to settle, find investors and launch their business.

But insights generated by a database that we've built indicate that new businesses can be located outside of the technology hubs and still attract investors. Our analysis showed that regions with more crowdfunding activity also attract more angel investors.

Built with help from the Kauffman Foundation and the National Science Foundation, our CrowdBerkeley database includes data on more than 1.2 million crowdfunding campaigns, mostly on Kickstarter but also on CrowdRise (which tracks charitable fundraising activities) and Kiva (an international platform that generates seed money for businesses in developing nations). Through looking at the Kickstarter data, we saw that geographic areas with lots of crowdfunding campaigns -- many of them in the Midwest or outside the typical entrepreneurial hubs -- also drew large numbers of angel investors. Importantly, crowdfunding seems to unlock more angel investors deploying capital into these regions.

Significantly, the crowdfunding was not a substitute for traditional investment, but served as a marker that helped angels find businesses that were already vetted by smaller investors and potential consumers. We've also noted that the link between crowdfunding and angel investment has grown stronger over time. Similar patterns have been observed in venture capital investment as well (Sorenson et al, 2017).
We studied approximately 312,000 Kickstarter campaigns between 2009 and 2016, looking at project titles and descriptions, locations, founder details, fundraising goals and the actual amount collected, project outcomes and comments from backers. We then compared these projects with data from Crunchbase, an open source database that tracks new ventures and fundraising activity. We found that a $10 \%$ increase in a region's crowdfunding activity resulted in a $4 \%$ increase in angel investing. The link was strongest for technology campaigns.

These insights come at a time when many are searching for ways to improve the economic vitality of regions outside the traditional entrepreneurial meccas. Right now Silicon Valley, New York City and Boston receive $75 \%$ of all venture capital funding. (https://www.businessinsider.com/steve-case-rise-ofthe-rest-revolution-startup-culture-2018-5) AOL Founder Steve Case's initiative, "Rise of the Rest," (https://www.revolution.com/entity/rotr/) strives to spread investment, opportunities and prosperity to other parts of the US. Studies by Olav Sorenson (https://eiexchange.com/content/259-home-field-advant age-works-in-business-as-well-a? search=Sorenson) and others have pointed out that entrepreneurs who manage to launch a business close to home enjoy more social capital from longstanding connections, which can help them attract investment and customers.

Crowdfunding is emerging as a non-traditional path to helping new companies find the early-stage funding they need. Our research shows that crowdfunding can not only give companies the seed money to launch, but can also attract the next round of investors by identifying businesses that already been vetted by potential customers. Moreover, crowdfunding may offer founders additional flexibility because it doesn't require them to give up equity, as traditional investors would demand.

In the future we plan to look more closely at the link 
between crowdfunding, the outcomes for businesses, and its link to the vitality of a region. We also hope to look at the full range of how people define "entrepreneurship," from mom-and-pop businesses to high-growth ventures, and to generate insights that spur new policies for economic growth.

\section{The Takeaway:}

- A lot of promising companies are located outside the dense technology hubs where investors typically look for them. Smart angel investors should study crowdfunding activities to find businesses that have already been vetted by their potential markets.

- For founders whose companies are outside the big startup hubs, crowdfunding might be a viable initial source of funding that sets the stage for the next round.

- Many potential angel investors want to invest closer to home. Crowdfunding allows these potential investors to find opportunities in unexpected places, as long as they are supported by a big enough crowd.

- Crowdfunding may also provide a mechanism for potential consumers to give feedback that makes a business idea even better, and thus more attractive to subsequent investors. Early validation can also help the entrepreneur secure better terms with manufacturers.

- Our full study and instructions for using the CrowdBerkeley data base are available here (https://www.sciencedirect.com/science/article/a bs/pii/S0048733317301208) for researchers, investors, policymakers and others with some technical know-how to analyze its contents.

\section{References}

Sandy Yu, Scott Johnson, Chiayu Lai, Antonio Cricelli and Lee Fleming, Crowdfunding and Regional Entrepreneurial Investment: an Application of the CrowdBerkeley Database (https://www.sciencedirect.com/science/article/abs/pii/S 0048733317301208), Research Policy, Volume 46, Issue 10

\section{Read More:}

"Home Field Advantage" Works in Business as Well as Baseball(https://eiexchange.com/content/259-home-fiel d-advantage-works-in-business-as-well-
a?search=Olav)

Additional Search Terms: getting money for my business, attracting investment, attracting investors, finding investors 